\title{
EL MUNDO ÁRABE AL INICIO DE LA "GUERRA FRÍA”: ¿DESCOLONIZACIÓN O COLONIZACIÓN?
}

\author{
Dra. D. ${ }^{a}$ Maria Dolores Algora Weber \\ Universidad San Pablo CEU. Madrid. España
}

\begin{abstract}
"En general, la politica colonial de las potencias europeas no se orientó deliberadamente hacia la emancipación. Sin embargo, incluso cuando parecia que se oponia a toda evolución o que reforzaba la servidumbre, la presencia de los europeos llevaba en si misma el germen de la liberación. A la larga, la actividad de administradores que imponian la paz, sometian a la población a obligaciones como el empadronamiento, el pago de impuestos, las vacunaciones, a veces al servicio militar y con menos frecuencia la asistencia a la escuela, determinaba el desarrollo de un sentimiento de comunidad que se afirmaba dentro de los limites trazados por la repartición europea, y no de los de la identidad étnica o de las corrientes históricas tradicionales. Fueron los europeos los que conscientemente o no, proporcionaron fronteras politicas a los futuros nacionalismos"'.
\end{abstract}

Las palabras de Henri Grimal describen significativamente una de las realidades que acontecieron en la sociedad internacional al término de la Segunda Guerra Mundial. El conflicto propició un relevo en las potencias directoras del mundo. Frente al debilitamiento europeo, emergían definitivamente dos fuerzas: Estados Unidos y la Unión Soviética. Ambas naciones compartian el rechazo al sistema colonial. Esta nueva realidad inevitablemente hubo de afectar al viejo continente y a sus posesiones de ultramar, las cuales se fueron convirtiendo en los últimos vestigios de su tradicional influencia.

De acuerdo con esta transformación, las grandes potencias defendian una doctrina descolonizadora a través de las Naciones Unidas. Pronto se sumaron a éstas los países afectados, iniciando desde ahí su recorrido hacia el "Movimiento de los No Alineados". Mientras este cambio se consolidaba, los Estados europeos cifraban su prestigio internacional precisamente en el mantenimiento de lo que era ya insostenible: los imperios coloniales. En este sentido, si las independencias de aquellos territorios terminaron por alcanzarse, se debió más a la fuerza irresistible de un nacionalismo, que había salido reforzado de los años de la contienda y se vio amparado por el foro internacional, que a los deseos emancipadores de los pueblos colonizadores. En otras palabras, las antiguas metrópolis se vieron sumergidas

1 GRIMAL, Henri. Historia de las descolonizaciones del siglo XX. Madrid, IEPALA, 1989. Pg.59. 
en un ámbito que se mostraba sumamente contradictorio para su posición: ¿la descolonización según las Naciones Unidas o el imperialismo según sus propios intereses?

Este dilema se vio acentuado y matizado con el inicio de la "Guerra Fría". Con la division del mundo en dos bloques enfrentados, Estados Unidos y la Unión Soviética, el occidente europeo continuó su progreso político y económico con el apoyo americanoz.

Al mismo tiempo, Estados Unidos se convirtió en el portavoz de los pueblos dependientes. Así condicionó el cómo y cuándo se debía otorgar la independencia. En consecuencia con la Doctrina Truman, el "peligro rojo" que amenazaba al mundo occidental desde el Este, obligaba a Norteamérica a calcular todas sus estrategias geopolíticas de manera que la retirada de Francia y Gran Bretaña, no se sustituyera por la presencia soviética.

En suma, se podría decir que en materia colonial durante la postguerra, se establecieron dos corrientes paralelas que con el tiempo tendieron a reconciliarse, la de las grandes potencias enfrentadas y la de las potencias europeas.

Nuestro objetivo en el presente estudio es la exposición de la actitud de esta sociedad internacional que exigía el "desmoronamiento" de los imperios coloniales, contrastada con los intentos de cooperación franco-británicos con el fin de mantenerlos.

\section{LAS GRANDES POTENCIAS Y LAS RESOLUCIONES DE LAS NACIONES UNIDAS EN 1945}

La política descolonizadora no era original de los años de la posguerra de la Segunda Guerra Mundial. En algunas de las declaraciones que inspiraban la politica exterior de Estados Unidos desde el siglo pasado ya se encuentran antecedentes, tales como la "Doctrina Monroe" de 1823. Mucho después, otros principios de indudable valor histórico como fueron los "Catorce Puntos" del Presidente Wilson de 1918, la "Carta del Atlántico" firmada por F.D. Roosevelt y W. Churchill en 1941 y la "Declaración de las Naciones Unidas sobre la independencia nacional" del Departamento de Estado en 1943. Todos culminaron con la formulación de lo que se vino a denominar "el Derecho Internacional de la Descolonización", cuyo principal instrumento fue la Organización de las Naciones Unidas.

Las resoluciones emitidas por este organismo en los años que siguieron al conflicto, estuvieron claramente marcadas por las doctrinas que habian ido perfilando la política norteamericana, una de las naciones que en aquellos momentos se erigía como dominadora del foro internacional.

La Conferencia de San Francisco del 26 de junio de 1945, siguiendo lo acordado en Yalta, clasificó las zonas a descolonizar en grandes conjuntos: "Territorios no autónomos",

2 Europa a finales de la Segunda Guerra Mundial hubiera querido ser una "Tercera Fuerza", un poder mediador entre las dos superpotencias, pero las condiciones comentadas lo impidieron. Ese papel quedó reservado para el "Tercer Mundo" desde finales de los años cincuenta.

CALVOCORESSI, P., Historia política del mundo comtemporáneo. De 1945 a muestros dias. Madrid, Akal/Universidad, 1987. Pg. 127.

YOUNG, J.W. France, The Cold War and the Western Alliance, 1944-1949. French Foreign Policy and the postwar Europe. Londres, Leicester University Press, 1990. Pg. 168-169. 
incluidos una serie de enclaves aislados denominados "espacios estratégicos" (capítulo XI de la Carta de Naciones Unidas); y "Territorios tutelados" (capitulos XII y XIII).

La situación de "los Territorios no autonomos", como pasaron a denominarse las antiguas colonias, quedó determinada por las "potencias administradoras", anteriormente metrópolis. Las obligaciones de éstas eran de carácter general, se indicaba que debían conducir a estos paises hacia el autogobierno y se declaraba que los intereses de las habitantes estaban por encima de todo. Se aceptó el compromiso de informar regularmente a las Naciones Unidas, pero no se preveia ningún medio de control para que se cumplieran las condiciones redactadas. Por tanto, aunque el Consejo de Seguridad se preocupara por la situación de estos pueblos dependientes, no tenía ninguna competencia en los asuntos coloniales.

La Unión Soviética, por su parte, también mantuvo una posición contraria a los imperios coloniales. Al iniciarse los años de la posguerra, su acción parecía que iba a ser acorde con la de los aliados, con los que habia formado filas durante la contienda. Sin embargo las diferencias en esta materia surgieron muy pronto. Comenzaron a raíz de una propuesta americana, que pretendía limitar la evolución de los territorios dependientes: los "Territorios no autónomos", colonias, únicamente podrían alcanzar la autonomía; los "tutelados", antiguos mandatos de la Sociedad de Naciones, así como los territorios arrebatados al enemigo como consecuencia del conflicto y los que voluntariamente aceptaran la tutela, serían los únicos para los que quedaria prevista la independencia; y por último, los "espacios estratégicos" del Pacífico quedarían bajo control de los Estados Unidos al margen del organismo internacional.

La delegación moscovita pretendió que todos los territorios pasaran a ser considerados como "tutelados"; pero Washington, que contó con el apoyo europeo, hizo prevalecer la clasificación anterior, pues era la que tan sólo unos meses antes, se había acordado en la Paz de Yalta ${ }^{3}$.

\section{LOS CAMBIOS DERIVADOS DE LA GUERRA FRÍA DESDE 1947}

Con el estallido de la "Guerra Fría" desde 1947, la Unión Soviética acabó por concebir las cuestiones en materia colonial, como el resultado de los intereses económicos de Occidente -nuevamente el imperialismo-. A partir de entonces, resucitaron las viejas teorias anticapitalistas, fundamentadas en el marxismo. La aportación doctrinal soviética a esta corriente internacional, encontró su cauce de difusión en las élites burguesas de aquellos territorios. De este modo, dentro del mundo colonial fueron tomando forma definitivamente los partidos nacionalistas, algunos de los cuales ya tenían sus antecedentes en el periodo de entreguerras. Pero en los años que siguieron al conflicto, intensificaron su lucha por una libertad que debería ser concedida por Occidente. Estas formaciones políticas autóctonas 
contaron con el apoyo de los partidos comunistas, los cuales también adquirieron un mayor peso en Europa por aquellos años. Lo cierto es que, ya fuera desde las colonias como desde las propias metrópolis por sus circunstancias internas, la realidad fue que estos territorios vinieron a constituir uno de los principales ejes del enfrentamiento en el que derivaron las dos ideologías, la marxista y la capitalista.

La evolución de las relaciones entre las potencias directoras a partir de entonces, obligó a introducir modificaciones en esta política anticolonial, que aun manteniendo sus principios básicos, fueron matizándola a la hora de sus aplicaciones concretas. En este sentido, los planteamientos geopolíticos adquirieron una relevancia tal, que prácticamente hicieron inviables las resoluciones de las Naciones Unidas. El apoyo norteamericano al anticolonialismo comenzó a ser pendular. Mientras que "para los nacionalistas de Asia y Africa, este cambio de actitud equivalia a algo que oscilaba entre la evasiva y la traición", no ocurrió lo mismo para los colonizadores. De estas circunstancias se beneficiaron las naciones administradoras, especialmente Francia y Gran Bretaña. Éstas se debatian en el seno del organismo internacional por conservar sus derechos coloniales, frente a la influencia cada vez mayor, que en esta materia tenía el grupo asiático-árabe e iberoamericano.

Este fue el origen de la contradicción a la que nos referíamos al plantear nuestro estudio: la necesidad de mantener posiciones estratégicas se enfrentaba al espiritu descolonizador de la Conferencia de San Francisco. Es más, la redacción concreta de los textos jurídicos que pretendian recoger esta política, dejaba una puerta abierta en la que los Estados administradores justificaron sus gestiones una vez que el mundo estuvo dividido en dos bloques. En otras palabras, se sobreentendía la validez del anticolonialismo, siempre y cuando esta realidad no fuera en contra del "sistema de paz y de seguridad internacionales". De esta manera, mientras en las Naciones Unidas se defendía el "autogobierno" de todos los pueblos del mundo, en la práctica lo único que se conocía era una nueva forma de "dependencia": "el neocolonialismo"s.

Como muestras de este giro, podemos citar varios casos. Por ejemplo, la negativa de Estados Unidos a adherirse a la condena del colonialismo, que se hizo en la Conferencia Interamericana de Bogotá en 1948. Asimismo la corriente contraria a la descolonización, que obligó a los alternativos gobiernos norteamericanos, a mantener un equilibrio entre las distintas tendencias en el seno del Congreso desde 1950. O bien, la oposición que mantuvieron a la resolución de Naciones Unidas, promovida por los paises árabes, asiáticos e iberoamericanos con el fin de incluir el "Derecho a la Autodelerminación de los pueblos" como uno de los principios legales de la Declaración de los Derechos Humanos.

En resumen, las palabras de Julius W. Pratt eran bastante esclarecedoras acerca de la evolución que se había producido en el seno de esta corriente descolonizadora, que ocupó los foros internacionales al término de la guerra:

5 NKRUMAH, K.: Neocolonialismo, la riltima etapa del imperialismo. México, Siglo XXI, 1966. 
"Desde 1945, a pesar de haber afirmado en varias ocasiones su simpatia por todos los pueblos que aspiran a la independencia, Estados Unidos se ha encontrado con frecuencia en aprietos por el entusiasmo y el impetu del auge del anticolonialismo y por la táctica de hostigamiento de su apoyo: el comunismo. Ha intentado canalizar este empuje hacia la celebración de acuerdos amistosos con las potencias denominadas coloniales. Con esta actitud no ha conseguido las simpatias de ninguno de los bandos enfrentados".

\section{LOS IMPERIOS COLONIALES EN EL MUNDO ÁRABE}

Lo dicho refleja la evolución en la actitud de las potencias hegemónicas, pero mientras tanto, ¿qué ocurría con las tradicionales naciones imperialistas de la historia contemporánea, como eran Francia y Gran Bretaña?. Para estos paises europeos, la descolonización no era únicamente una cuestión doctrinal, sino una cuestión esencialmente territorial. La nueva consideración colonial era para estos una amenaza, traducida en una pérdida de poder en la esfera mundial. Paralelamente, el "Tercer Mundo" se encontraba en ascendente motivación, por el caríz que a su favor iban tomando las resoluciones de las Naciones Unidas.

Esto explica el contraste que se percibe entre las posiciones de los viejos imperialistas y las nuevas potencias. Por eso los objetivos de las relaciones franco-británicas en el mundo árabe en general, y el norteafricano en particular, no se ajustan exactamente a las pretensiones de los foros internacionales. Las metrópolis eran conscientes, por presiones "morales" y políticas, que no podian relegar por más tiempo la independencia que reclamaban los colonizados. Pero la aceptación de esta realidad y las respuestas que se dieron a las reivindicaciones, no fueron las mismas?.

Por esta razón antes de analizar la cooperación de Francia y Gran Bretaña en esta materia, conviene recordar cómo ambas metrópolis habian resuelto las nuevas condiciones en sus imperios.

\section{DOS MODELOS DE DESCOLONIZACIÓN: LA ASIMILACIÓN Y LA ASOCIACIÓN}

El equilibrio político que había existido entre las metrópolis y sus colonias se rompió con el estallido de la Segunda Guerra Mundial. Las derrotas iniciales de las potencias aliadas les proporcionaron un enorme desprestigio ante los pueblos sometidos por ellas. Estas circunstancias contribuyeron al despertar de los nacionalismos en aquellos territorios.

Por tanto, al término del conflicto, los poderes imperialistas se vieron arrastrados por las corrientes descolonizadoras y el ascenso paralelo de los movimientos independentistas autóctonos. Ello les obligó a reconsiderar la dominación de sus posesiones. Aceptaron la

6 GRIMAL,H.: Op. Cit., pp. 17.

7 TRUYOL Y SERRA, A. La Sociedad Internacional. 5 Edic, Madrid, Alianza Universidad, 1985. P. 107. 
introducción de reformas, dotaron a los territorios de un nuevo estatuto, siempre y cuando no alteraran su supremacía y la conservación de sus intereses.

Para Francia el resultado de este proceso fue la creación de la "Unión Francesa", recogida en la constitución de la IV República en 1946. El nacimiento de esta comunidad, compartida por la metrópoli y sus territorios coloniales, tuvo lugar en aquel clima internacional de enormes contrastes ideológicos. Estas circunstancias contribuyen a explicar la ambigüedad que se expresaba entre el Preámbulo y el Título VIII, que daban lugar a esta fórmula. Mientras que el texto del primero era una declaración de principios en un tono anticolonial, el segundo limitaba el acceso a la autonomía política de los territorios del imperio

Esta confusión a la hora de legalizar la obligada descolonización, ponía de manifiesto que Francia, en realidad, estaba dispuesta a adoptar una política de firmeza en la cuestión. De ahí que se optara por el principio de "asimilación", para definir el vínculo entre los miembros de la unión. Esta fórmula era un instrumento que bajo una aparente descolonización permitía el mantenimiento del imperio colonial francés.

Esta política conservadora que mantuvo el gobierno de París, tenía su justificación en la herencia dejada por la guerra. En primer lugar, la enorme debilidad internacional que le había proporcionado la división interna durante aquellos años; en segundo lugar, la deplorable situación económica en la que había quedado el país; y por último, una creciente obsesión, en Europa en general, producida por una posible reacción de Moscú, especialmente desde el estallido de la "Guerra Fría". Para la nueva república todo ello parecía tener una solución en el marco colonial. El imperio se convirtió en el único medio para recuperar la consideración exterior perdida, al mismo tiempo que proporcionaba una fuente de abastecimiento de materias primas imprescindibles para la reconstrucción del país, y finalmente, desde 1947, constituía un territorio de repliegue hacia el norte de África, en el caso de producirse la temida invasión soviética?.

En este sentido, ya en la postguerra, todavía resultaban elocuentes las palabras que $R$. Pleven, comisario de colonias de la "Francia Libre", habia pronunciado en 1944:

"Es precisamente ahora, cuando Francia es sin duda alguna más consciente que nunca del valor de su "Imperio" y de sus deberes para con él, cuando escuchamos una nueva doctrina que sostiene que no deberian garantizar las responsabilidades coloniales las naciones que lo han intentado durante siglos..., sino algin organismo internacional al que se atribuya, por una petición de principio, la virtud cardinal de la justicia (...) y las de competencia y actividad (...). Ni el interés de las poblaciones ni sus deseos podrian ser satisfechos mediante una reforma que transfiriera a un órgano de gestión, en nombre de la colectividad, la acción colonizadora, es decir, liberadora de los grandes azotes que asolan a las sociedades primitivas, ya sean las enfermedades, la ignorancia, la superstición, la tirania..."'.

8 GRIMAL, H.: Op. Cit., p. 130

MONTASSIER, V.A. Les Annés d'apr s-gwerre, 1944-1949. Paris, Fayard, 1980. P. 146.

9 Estos planes se concretaron en la denominada Operación "Rainbow" en 1948. Ver, FALIGOT,R. \& PASCAL, K. La piscine. The French Secret Service since 1944. Nueva York, Basil Blackwell Inc., 1989. P. 66.

10 GRIMAL,H. Op. Cit., p. 124. 
Por tanto, Francia salió de los cuatro años de ocupación, mucho más unida a la idea de mantener el imperio, que Gran Bretaña. De este modo se entiende que la descolonización francesa, tardara largo tiempo en ser aceptada y se convirtiera en un proceso sangriento. No habían faltado esfuerzos destinados a reducir esta violencia, el propio general De Gaulle en la Conferencia de Brazzaville, había propuesto una comunidad como una gran empresa capaz de unir a los franceses y sus colonias. Sin embargo, el resultado de la emancipacion territorial, contraria a la voluntad del Quai d'Orsay, les proporcionó dos guerras de ocho años: Indochina y Argelia". Además de problemas graves en Madagascar, Túnez y Marruecos, y finalmente, un verdadero golpe de Estado militar en mayo de 1958. En otras palabras, la disolución imperial fue un factor de los que más transformó no sólo la política exterior, sino la interior del país. Terminó con la IV República francesa y dio paso a la V República, al frente de cuya presidencia se situaría el propio De Gaulle ${ }^{12}$.

Gran Bretaña, por su parte, comenzó el proceso de emancipación territorial mucho antes del conflicto mundial. Tras la pérdida de su primer imperio -las Trece Colonias americanas en 1776-, los británicos habían aprendido a evitar los errores que le impidieran mantener el segundo. Sabían que la acción represora de la metrópoli sólo podía conducir a la revolución, a la guerra y al riesgo de la humillación ${ }^{13}$.

Esto explica que en 1907, en pleno auge del fenómeno imperialista, ya el gobierno londinense acordara el uso del término "dominio" para aquellas posesiones de poblamiento blanco con gobiernos responsables. En la conferencia imperial de 1926, los dominios alcanzaron una independencia virtual. Pero mucho más importante, fue la decisión tomada desde entonces acerca de transformar el imperio en una comunidad. En diciembre de 1931 el Estatuto de Westminster legalizó los nuevos principios, constituyéndose en el Acta fundacional de la Comunidad Británica o "Commonwealth" de naciones independientes.

Los nuevos Estados establecieron un vínculo económico preferencial con la antigua metrópoli. Por tanto, en vísperas de la Segunda Guerra Mundial, el Imperio Británico representaba una gran variedad de territorios ${ }^{14}$.

Durante el conflicto, el nacionalismo emergente en los paises africanos y asiáticos afectó a las posesiones británicas, como al resto. El gobierno de Londres tuvo que enfrentarse a los movimientos autóctonos de sus colonias, a raíz de las repercusiones de la Carta del Atlántico sobre el mundo colonial en 1941. W. Churchill intentó matizar el asunto. Las declaraciones del documento, concedian el derecho a elegir su propia forma de gobierno a los pueblos europeos bajo dominación nazi en la guerra, pero las ansias de independencia

11 Muy descriptivas de la situación imperial francesa son las palabras de Michel Carver al juzgar que la única suerte con la que contó Francia en su acción colonial fue que tuvo que enfrentarse al problema argelino (19541962), una vez que se había podido deshacer del igualmente intratable problema de Indochina (1946-1954). CARVER, M. War since 1945. (Revised Edition). Londres, The Ashfield Press, 1990. P. 121.

12 DUROSELLE, J.B.: "Politique intérieure et politique extérieure" en la revista Relations Internationales, $\mathrm{n}^{\circ} 37$. primavera 1984, Pp. 7-16.

13 LAPPING, B. End of Empire. Nueva York, St. Martin's Press, 1985. P. 7.

14 MARTINEZ CARRERAS, José U. Historia de la descolonización 1919-1986. Las independencias de Asia y Africa. Madrid, Istmo, 1987. P. 19. 
de los pueblos colonizados favorecieron la extensión de estos principios a su propia situación.

Son elocuentes a propósito del clima de contradicciones, las palabras del primer ministro en aquella ocasión:

"No intervenimos en esta guerra con ánimo de lucro ni de expansión, sino únicamente por un sentimiento del honor y por cumplir nuestio deber de defensores del derecho. Sin embargo, quiero ser claro: lo que tenemos, lo conservaremos. No me he convertido en primer ministro de Su Majestad para liquidar el Imperio Británico"1s.

Sin embargo al término de los enfrentamientos, la fuerza imparable del nacionalismo, así como la inmediata desaparición de Churchill -y su posterior moderación dado que volvió a ocupar el mismo cargo entre 1951 y 1955-, impidieron que se cumpliesen sus pretensiones. La bancarrota después de la guerra aceleró la desintegración colonial. Los ingleses, conscientes de las nuevas circunstancias mundiales, con una visión realista, accedieron a ampliar la nueva concepción imperial a sus posesiones africanas y asiáticas. El Foreign Office asimiló que el único medio para continuar obteniendo un beneficio optimo de estos territorios, era acercarse a las aspiraciones emancipadoras de los pueblos autóctonos, incluso prestarles todo su apoyo para que ésta perdurara una vez alcanzada. Por tanto, la fórmula descolonizadora adoptada fue la "asociación", una estructura confederada, que resultó ventajosa tanto a los nuevos Estados soberanos como a Gran Bretaña.

En definitiva, tanto Francia como Gran Bretaña se intensificaron para conservar sus respectivos imperios. Ahora bien, aunque su objetivo era el mismo, la ejecución dio resultados muy distintos. En gran medida se explica por el valor que cada metrópoli concedía a sus colonias. Para Francia era una cuestión socio-politica relacionada con su prestigio internacional, mientras que para Gran Bretaña, el valor era económico y geoestratégico.

\section{DEL MARCO LEGAL TEÓRICO A LOS PROBLEMAS INTERNOS EN LOS TERRITORIOS FRANCESES Y BRITÁNICOS}

La "Unión Francesa" y la "Commonwealth" se enfrentaron a los problemas internos que Francia y Gran Bretaña tenian en sus colonias árabes -presentes o del pasado-, que si bien son las que en nuestro estudio nos interesan, no eran piezas aisladas dentro del decadente ámbito imperial. La evolución de las independencias en otras regiones del mundo, se reflejó inevitablemente en los territorios árabes, puesto que todos compartían las instrucciones y proyectaban los efectos de sus nacionalismos sobre las políticas metropolitanas. Es decir, la descolonización del mundo árabe no fue ajena a lo que estaba ocurriendo en Indochina, por ejemplo en el caso francés, o en la India en el caso británico.

Gran Bretaña experimentó importantes problemas internos en sus posesiones, a pesar de haber promovido un sistema de descolonización más flexible que el francés. En los años

15 GRIMAL, H.: Op. Cit. P. 123. 
que tratamos, sus conflictos coloniales en el mundo árabe no se originaron siempre de la dominación directa de los territorios, sino que en algunos casos procedian de su presencia militar en la zona. Siendo tensas y ambiguas las relaciones de Londres con los países árabes desde sus primeros momentos, no se consiguió que ninguno de estos Estados perteneciera a la Commonwealth.

En el Próximo Oriente, a los británicos no les importó cuáles fueran los medios a utilizar, la fuerza o la política. Mantuvieron su influencia a toda costa. Su tradicional sistema colonial de adaptación a los movimientos nacionalistas, sucumbió ante los intereses estratégicos de la zona, por otra parte imprescindibles para la consecución de los económicos. Por lo tanto, actuaron al margen de los sentimientos de las poblaciones árabes, sometiendo siempre la evolución de los acontecimientos a sus necesidades. Esta política desacreditó a Gran Bretaña como potencia progresista en su acción colonial. Reputación que inmediatamente fue contrarrestada por los ejemplos descolonizadores de la India, Ceilan, Birmania, Sudán, Ghana, Nigeria, etc. Es más, todos estos nuevos Estados se integraron en la Commonwealth a diferencia de los anteriores, como muestra de la aceptación del modelo británico. Egipto e Iraq habian adquirido la independencia virtual mucho antes de la Segunda Guerra Mundial, en 1922 y 1932 respectivamente, y Transjordania lo hizo inmediatamente después, en 1946.

No obstante, Londres mantuvo relaciones con sus antiguas posesiones a través del ejército. En el caso egipcio, la amenaza de las aspiraciones imperialistas de Mussolini sobre Etiopia, permitió la ocupación de la zona del Canal de Suez por las fuerzas británicas por veinte años desde 1936. Durante el conflicto internacional éste fue un enclave importantísimo para los aliados. El gobierno de Londres decidió reforzar su presencia, imponiendo al rey Faruq, el nombramiento de un primer ministro pro-británico, Nahas Pasha ${ }^{16}$. Además preparó la situación posbélica, promoviendo la asociación de los Estados árabes en una Liga, que sería el instrumento de su influencia. Para esto el Foreign Office se valió del apoyo de Iraq. La contienda le había dado la oportunidad de implantar nuevamente sus tropas allín ${ }^{17}$. Nuri el-Said, primer ministro iraquí, fue quien fomentó el concepto de unidad política en el Creciente Fértil, pero el resultado no fue la unión que los ingleses esperaban. El papel que debía haber tenido Iraq, como agente occidental, fue rápidamente anulado por el peso que Egipto tenía para el resto de los miembros: Siria, Líbano, Transjordania, Arabia Saudí y Yemen.

Por tanto, a los problemas con el gobierno egipcio causados por la presencia militar en Suez, hubo que a añadir el liderazgo de este pais en el ámbito árabe desde 1945. Egipto estaba cada vez más dispuesto a promover todos los movimientos que condujeran a una expulsión de los occidentales de la zona del Próximo Oriente. Pero a pesar de estas dificultades,

16 VATIKIOTIS, P.J.: The history of Egypt from Muhammad Ali to Mubarak. $3^{\text {a }}$ Ed. Londres, Butler \& Tarnner Ltd., 1985. Pp. 317-371.

17 BRANS, H.W. Inside the Cold War. Loy Henderson and the rise of the American Empire, 1918-1961. Nueva York, Oxford University Press, 1991. Pp.116-125. 
los británicos no estaban dispuestos a abandonar la zona antes de lo acordado en los tratados.

La situación se hizo más compleja desde 1947. Gran Bretaña se encontraba en una grave crisis financiera, que no le permitía mantener la seguridad del Mediterráneo oriental. Como consecuencia de esta situación, solicitó a Estados Unidos que asumiera sus responsabilidades en Grecia y Turquía. Pero esto no era más que una parte de su problema, puesto que a lo largo del conflicto había contraido con Iraq y Egipto una cuantiosa deuda económica, a la que era cada vez más difícil hacer frente. Todas estas circunstancias motivaron la "Doctrina Truman", provocando la Guerra Fría.

Al lamentable panorama británico se sumó el fracaso de su política en Palestina. Este mandato le fue adjudicado por la Sociedad de Naciones y le ocasionó las situaciones más graves en las que se encontró el imperio. Londres como gobierno administrador fue incapaz de conducirlo hacia la independencia de forma pacifica. Finalmente tuvo que transferirlo a las Naciones Unidas, ocasionando enormes críticas al gobierno laborista entonces en el poder. El último funcionario británico abandonó Palestina el 14 de mayo de 1948, al día siguiente fue proclamado el Estado de Israel, inmediatamente reconocido por Truman y Stalin. Para la población árabe, este enclave siempre significó un subterfugio imperialista para el mantenimiento del poder anglo-americano en el Próximo Oriente. La pésima descolonización de este territorio condujo a un enfrentamiento cada vez más exacerbado del extremismo y nacionalismo árabe contra el sionista. Graves enfrentamientos que se prolongan hasta nuestros días.

Inevitablemente la posición británica en el Próximo Oriente se había debilitado. En estas condiciones el gobierno de Londres tuvo que revisar sus tratados en la región. El rey Adbullah de Transjordania permitió la permanencia de las tropas británicas en su territorio durante otros veinticinco años. Sin embargo, egipcios e iraquíes rechazaron la renovación de los acuerdos.

Los territorios británicos de la península Arábiga -Kuwait, Bahrain, Qatar y Aden- estuvieron dominados directamente durante más de un siglo desde $1839^{18}$. Su posición estratégica fue el mayor valor que se les atribuyó, dado que fueron enclaves fundamentales que facilitaron la pervivencia de la influencia británica en la India, antes y después de su independencia. Por tanto, el interés por esta zona estuvo muy vinculado a la trayectoria de la descolonización en Asia central. La presencia militar fue justificada con múltiples argumentos, tales como la necesidad de contener el avance comunista, evitar que los regímenes políticos se escoraran hacia posiciones extremistas, la cooperación con Estados Unidos en materias de defensa y seguridad, el abastecimiento de petróleo a occidente, etc. En definitiva, todo ello entendido en el contexto de la "Guerra Fría", fue lo que permitió mantener el imperio en decadencia, durante más tiempo de lo que pudieron hacerlo sus aliados en otras zonas.

Francia también tuvo graves problemas. Los territorios árabes del Próximo Oriente, Líbano y Siria, adquirieron sus independencias de hecho en 1944. Poco después, en 1945 y

18 Kuwait obtuvo la independencia en 1961, Aden y sus protectorados en 1967, y Bahrain y Qatar en 1971. 
1946 respectivamente, fueron evacuadas las tropas francesas de sus territorios de manera definitiva. Por tanto, los territorios árabes que a Francia le quedaron en la postguerra fueron los del norte de África, integrados dentro del modelo descolonizador mientras fueron dependientes.

Antes de referirnos a las posesiones del Magreb, conviene detenerse en otro aspecto. Paralelamente a la pérdida de la influencia en la zona del Próximo Oriente, el escenario posbélico del Asia suroriental agravó la situación del imperio francés. Los problemas de Indochina acapararon las decisiones más importantes tomadas por Francia en materia colonial. Se concentró la atención en una guerra de desgaste, que en realidad a quien interesaba era al gobierno de Washington. Los americanos vieron en el dominio francés de aquel territorio el medio para impedir la expansión comunista desde China durante la "Guerra Fría". Estas circunstancias tuvieron un doble efecto. Por una parte, con el transcurso de los acontecimientos, incitaron a París a aferrarse cada vez más a sus territorios en Africa, puesto que se convirtieron en sus últimas colonias. Por otra, el conflicto de Indochina requirió enormes recursos materiales y humanos de una Francia asolada, lo que socavó el desarrollo de una política más de acuerdo con sus intereses, capaz de frenar las aspiraciones nacionalistas en las posesiones magrebíes.

En este contexto hay que entender la incidencia que tuvo en Francia el nacionalismo árabe norteafricano, que aunque resurgió a lo largo de la Segunda Guerra Mundial, alcanzó su máxima expresión en los años de la postguerra. Un factor que tuvo un peso especial, fue la creación de la mencionada Liga de Estados Árabes en 1945, instrumento que utilizaron los británicos para ejercer su influencia. La rivalidad egipcio-iraquí por mantener el liderazgo en el seno de la Liga, ponía de manifiesto en su transfondo el enfrentamiento entre una opción árabe propiamente dicha, y una opción mediatizada por Gran Bretaña. Esta solidaridad de intereses árabes, aunque fuera sólo en su fachada, aceleró la consolidación de los movimientos independentistas en plena "Guerra Fría". Así pues, Francia se encontró con enormes problemas internos y externos en sus últimas posesiones árabes. Conflictos cada vez más dificiles de resolver para la turbulenta IV República. Muy acertadamente, las palabras del líder marroquí Abd El Krim describian simbolicamente la decadencia del imperio francés:

"Francia hoy en dia es como un barco en una tempestad sin timón (...). Existe un fuerte viento soplando alrededor del barco y muy pronto la tempestad hará que se vaya al fondo del mar'!s.

Las posesiones francesas en el norte de África ocupaban prácticamente la totalidad de la extensión de esta zona y se concretaban en dos protectorados, Marruecos ${ }^{20}$ y Túnez, y un

19 Despacho $n^{\circ} 2766$ de la embajada de Estados Unidos en Egipto. Jefferson Patterson, encargado de negocios a.i., 28 de julio de 1947. National Record Center (N.R.C., Suitland, Md.). Embajada de Egipto, 1947.

20 Las posesiones coloniales de España en Marruecos y Sahara, no se tratan en el presente estudio, debido a que al inicio de la "Guerra Fría", el Régimen de Franco se encontraba al margen de las Naciones Unidas y no le afectó de manera directa la corriente descolonizadora, que aqui analizamos. De igual forma, que una vez realizado el ingreso de España en dicho organismo, la política de "provincialización" aplicada a esos territorios, evitó la interferencia de la acción internacional. 
departamento de ultramar, Argelia. Este último, en los años primeros de la postguerra, estuvo integrado en la "Unión Francesa" como prolongación del territorio metropolitano, tenía sus propios representantes tanto en la comunidad como en el parlamento de Paris.

Sin embargo, mucho más compleja aunque sólo en un principio, fue la situación de los protectorados. La estructura interna de estos se vio menos afecta por el imperialismo que en el caso argelino. Por esta razón, a la hora de articular la descolonización fue más dificil mantener unos lazos, de por sí inexistentes, entre la población árabe y el gobierno francés. Durante los años en los que todavía permanecieron dependientes, se originó la polémica acerca del futuro de estos Estados, una vez que se convirtieran en soberanos: vinculación o no a Francia. Este dilema provocó la división entre los árabes del norte de África. Se desligaron dos sectores, que si bien tenían en común la lucha por la independencia, se separaban en cuanto a la forma de concebirla. Los comunistas pretendian una independencia dentro del marco de la "Unión Francesa". Los nacionalistas, mucho más radicales, rechazaban esta opción y se encaminaban hacia la ruptura completa de los lazos con la antigua metrópoli una vez emancipados ${ }^{21}$. Este distanciamiento entre las posturas árabes perjudicó notoriamente al gobierno francés. Las campañas de prensa que ambos bandos desarrollaron a favor de su causa, acabaron mostrando los aspectos más negativos de la vinculación a París. Desde este núcleo, la negativa imagen de la IV República transcendió al resto del mundo árabe, donde Francia ya de por sí carecía de tradición arabófila.

Al iniciarse la "Guerra Fria" la fuerte inestabilidad que padecían los territorios del Magreb, no se limitaba a los enfrentamientos ideológicos de estos grupos recogidos en la prensa árabe, sino que a ello se añadian una serie de sucesos cotidianos que igualmente contribuyeron al deterioro de la acción francesa. En 1947 coincidieron en contra de la metrópoli, las repercusiones del viaje del Sultán de Marruecos a Tánger, los problemas derivados de la cuestión del "Emira Fawzia" en Túnez, la fuga del líder nacionalista Abd el Krim en Egipto... Fue el estallido definitivo de una carrera, que culminó con las independencias en el norte de África en 1956.

Libia supuso el punto de encuentro de franceses y británicos. Consecuencia de los acontecimientos bélicos había pasado a la administración de estas naciones, una vez que Italia había sido derrotada. En la inmediata postguerra, los gobiernos no llegaron a un acuerdo acerca del futuro de este territorio y se limitaron al envio de cónsules que permitieran estar al corriente de los movimientos nacionalistas, tanto de la zona como de las regiones vecinas ${ }^{22}$. En 1949 fue planteada esta cuestión en Naciones Unidas y se decidió otorgar su independencia en 1951.

21 Ni siquiera Soulier, secretario para los asuntos de Levante en la embajada francesa de El Cairo, logró convencer al tunecino Bourguiba y al marroquí Allal al Fassi para que aceptara una fórmula intermedia entre ambas posiciones. NATIONAL CENTER RECORD (N.R.C.), Suitland, Md. Embajada de Egipto, 1947. Despacho $n^{\circ}$ 349 del consulado general en Alejandria al departamento de Estado. Confidencial. Hooker A. Doolittle, cónsul general. 20 de junio de 1947.

22 Public Record Office (P.R.O.), Londres. F.O., 67711/Z3827. Despacho n ${ }^{\circ}$ (Z3827/52/69). Secreto. $22 / 4 / 1947$. 


\section{LOS INTENTOS DE COOPERACIÓN FRANCO-BRITÁNICOS EN MATERIA COLONIAL}

\section{Las bases del acercamiento}

La posguerra de la Segunda Guerra Mundial comenzó con una tensa relación entre París y Londres. Gran Bretaña, además cada vez mucho más próxima a la política de Estados Unidos, era una potencia de mayor peso que Francia en Europa. A pesar de estas dificultades los intentos de cooperación entre ambas naciones se mantuvieron latentes.

En el otoño de 1946, Churchill hizo un llamamiento a la unidad europea con el fin de recuperar la relevancia del Viejo Continente, en un mundo cada vez más dominado por Estados Unidos y la Unión Soviética. El secretario de Estado británico, Bevin, estaba muy interesado en una unión aduanera, que favoreciera la creación de un gran mercado, capaz de hacer la competencia al norteamericano. Estas consideraciones económicas condujeron a un acercamiento entre ingleses y franceses. El resultado fue la creación de un Comité Económico Anglo-Francés. Aunque muy lejos de una integración económica a gran escala, al menos significó el primer paso en un entendimiento en el que todavía quedaban enormes diferencias en muchos aspectos políticos.

En enero de 1947, coincidiendo con la nueva situación interna de la IV República, Bidault, ministro de Asuntos Extranjeros, comunicó a Cooper, embajador británico en París, la disponibilidad de su gobierno, para preparar un tratado de seguridad con Gran Bretaña. En pocos días el Foreign Office y el Quai d'Orsay se pusieron en funcionamiento con este fin. El resultado fue la firma del Tratado de Dunquerque el 4 de marzo. Suponía un compromiso de cooperación anglo-francés contra el resurgimiento de la política alemana ${ }^{23}$.

\section{La negociación de la cooperacion colonial}

A raíz del espíritu abierto en Dunquerque entre ambas cancillerías, se intentó trasladar la cooperación al ámbito colonial ${ }^{24}$. Gran Bretaña se mostró más favorable a la colaboración con Francia en los asuntos extra-continentales que en los europeos. Sin embargo una de las cuestiones que dificultó la asociación de ambos gobiernos en materia colonial fue la pretensión del Quai d'Orsay de ser considerado en el mismo terreno de igualdad por Londres, sin considerar las enormes diferencias que existían en los recursos que obtenian y con los que podian mantener sus imperios ${ }^{25}$.

Desde un principio esta cooperación cristalizó en dos ejes. Mientras los británicos deseaban la defensa de los territorios del Próximo Oriente, concretamente las cuestiones

23 YOUNG, J.W. Pp.135-136.

24 P.R.O., F.O. 371/67711, Z3178. Despacho n 610, secreto. Del Secretario de Estado británico, Emest Bevin, a Duff Cooper, Embajador en Paris. 13/05/1947.

Despacho $n^{\circ} 138,115,91,110$ y 238, confidencial. Del Foreign Office a W.E. Houstoun-Boswall. 28/06/1947.

25 YOUNG, J.W. Op. Cir., p. 227. 
de Egipto y Palestina ${ }^{26}$, los franceses se interesaban por el norte de África. No obstante, la conexión existente entre los problemas que surgían en una zona u otra, obligaban a una coordinación entre París y Londres. Por ejemplo, desde Túnez existía una corriente de inmigración judía clandestina hacia Palestina. La voluntad de acercamiento, no sólo alcanzaba a la acción política a desarrollar por las autoridades establecidas en aquellos territorios, sino también al necesario respaldo de unos y otros en el seno de las Naciones Unidas. Francia estaba despreocupada del organismo internacional, ya que por entonces no se preveía la llegada del asunto de las independencias magrebíes a la Asamblea General. Se centraba en la acción de los diplomáticos británicos instalados en las áreas francesas, a los cuales responsabilizaba de promover los movimientos nacionalistas contra la política de París.

Los intentos de colaboración se vieron determinados por las condiciones en las cuales se produjeron. A ello se sumaba precisamente en aquellos momentos la Doctrina Truman, que antes de finalizar el verano se habria convertido en la piedra angular de la "Guerra Fría".

Los primeros sintomas de una mejora de las relaciones coloniales anglo-francesas procedieron de Gran Bretaña, dado que en la agenda de Naciones Unidas del otoño de 1947, se incluirían la cuestión egipcia y la palestina. El Foreign Office mostró un gran interés por alcanzar un acuerdo con Francia, o al menos conseguir que su representante no dificultase las cosas en la Asamblea General ${ }^{27}$. Con este fin se intentó un acercamiento a los franceses, a través de la acción diplomática en el norte de África. Londres endureció su postura respecto a los movimientos nacionalistas árabes de la zona. A finales de marzo, Chauvel, secretario general del Quai d'Orsay, reconoció a Cooper el valor que para su ministerio supondría la colaboración de los cónsules británicos del Magreb y manifestó su deseo de que las mismas instrucciones fueran trasmitidas a los cónsules del Próximo Oriente. Dada la buena disposición británica, se aprovecharon aquellas conversaciones para plantear una iniciativa, que iba mucho más allá de la acción diplomática en los territorios coloniales. Francia propuso una completa coordinación en las políticas que ambas naciones deberían desarrollar

26 En cuanto a Egipto, Gran Bretaña desde el Tratado de 1936, mantenia su ejército en el territorio árabe. Simultáneamente desde los Acuerdos de 1899, y ratificado en el tratado mencionado, compartia con la monarquía egipcia el condominio sudanés. En 1946 fracasó un nuevo proyecto de acuerdo anglo-egipcio. En 1947, aunque la cuestión es llevada por Egipto al Consejo de Seguridad de las Naciones Unidas, no encontró una audiencia favorable a su posición. MARTłNEZ MONTÁVEZ, P.:"Egipto: De Faruq a Nasser". Pp.45-46.

En cuanto a Palestina, entre 1939 en que entró en vigor el Libro Blanco y 1948, el censo judio en aquel territorio evolucionó poco. En los años inmediatamente posteriores a la Segunda Guerra Mundial, la posición de Europa en general contra el pangermanismo propició un espiritu de conmiseración y apoyo al pueblo judio. El gobierno laborista inglés presidido por Atlee, se mostró favorable a esta causa en su mandato palestino. A ello hubo que sumar las presiones que en un principio ejercieron los Estados Unidos, partidarios de una inmigración sin restricción alguna. En cuanto se produjo el estallido de la "Guerra Fría", al margen de sus simpatias, Londres modificó esta politica. Sus intereses económicos y estratégicos se encontraban muy vinculados a los paises árabes. Desde entonces se mantuvo el Libro Blanco en vigor. SOLAR, D.: "El nacimiento de Israel". Pp. 77-80.

Ambos articulos en Historia Universal del siglo XX. La independencia árabe. El nacimiento de Israel. Madrid, Historia 16, Fasciculo ${ }^{\circ} 24,1985$.

27 P.R.O., F.O. 371/67711, Z3178. Despacho n 610, secreto. De Ernest Bevin a Duff Cooper. 13/05/1947.

Despachos $n^{\circ} 138,115,91,110$ y 238, confidencial. Del Foreign Office a W.E. Houstoun-Boswall. 28/06/1947. 
hacia el mundo árabe ${ }^{28}$. La respuesta de Gran Bretaña se hizo esperar algún tiempo, dada la polémica que en el interior del Foreign Office debió levantar la propuesta ${ }^{29}$.

Mientras tanto en el mes de abril, como consecuencia de esta mejora en las relaciones, se nombró un nuevo cónsul en Fez, núcleo del nacionalismo marroquí. El Foreign Office dejó claro que el objetivo de esta designación era establecer un punto de información para el conocimiento exacto del desarrollo de los movimientos independentistas, los cuales se encontraban en absoluta conexión con lo que ocurría en el resto de los países árabes ${ }^{30}$.

Por fin a mediados de mayo, Cooper conocia la posición de su gobierno respecto a la iniciativa de Chauvel. El primer ministro, Atlee, desestimaba la posibilidad de plantear una política común en el mundo árabe, pero no descartaba una cierta coordinación en las acciones. Efectivamente, las instrucciones de cooperación habian sido trasladadas a El Cairo, desde donde se comunicarian al resto de los embajadores como había sugerido el secretario general del Quai d'Orsay. A cambio, Massigli, embajador en Londres, debería asegurar que se produjera una correspondencia en esta actitud entre los diplomáticos del Próximo Oriente. Los funcionarios franceses debian mantener unas relaciones cordiales con sus homólogos británicos a fin de que sus diferencias en cuanto a las cuestiones de Palestina y Egipto no llegaran a traslucirse en la prensa árabe. Esto resultaria poco beneficioso para ambos gobiernos, dado que lo que ocurría en esta zona central, pronto se extendía por todo el Mediterráneo. En conexión con estos problemas, el Foreign Office solicitó la autorización al cónsul francés de Túnez, para que cooperara impidiendo la inmigración ilegal judía hacia Palestina. Se advertía que todas estas medidas serian inútiles, si los representantes en Naciones Unidas se criticaban mutuamente cuando estas cuestiones fueran planteadas ${ }^{31}$.

A pesar de que debía conducir a un mejor entendimiento, de la respuesta de Atlee a la iniciativa de París, se tradujo cierto tono de amenaza. No se estaban negociando los términos de una cooperación anglo-británica, sino que más bien se estaban exigiendo. Cooper recordo a Chauvel, que en virtud del acuerdo de la Entente Cordial de 1904, a Francia no le quedaba más alternativa que el respaldo de Gran Bretaña en Egipto, si pretendía una política similar para sus intereses en Marruecos. Mayor aún era esta extorsión del Quai d’Orsay, cuando se advirtió que de no producirse esta cooperación, inmediatamente sería invadida la prensa árabe con artículos que perjudicasen la ya de por sí deteriorada imagen francesa en el norte de Africa. Dadas las circunstancias, a finales de mayo los respectivos ministerios de

28 P.R.O., F.O. 371/67711, Z3178. Despacho $n^{\circ}$ 280, secreto, de Duff Cooper, al primer ministro C.R. Allee. 25/03/1947.

29 En algunos sectores se podian encontrar fuertes criticas. W. Blanch consideraba que la intención de los franceses cuando hablaban de una politica común, no se limitaba al simple envio de instrucciones a todos sus representantes británicos en el norte de África, sino que pretendían que no fomentasen el nacionalismo y defendieran la politica de París en cualquier lugar del mundo árabe donde fuera atacada, incluso en las Naciones Unidas.

P.R.O., F.O. 371/67712, Z5305. Minuta de William Blanch del Foreign Office.

30 P.R.O., F.O. 371/67711, Z3178. Despacho n610, secreto. De Emest Bevin a Duff Cooper. 13/05/1947. Despacho n 138,115,91,110 y 238, confidencial. Del Foreign Office a W.E. Houstoun-Boswall. 28/06/1947.

31 P.R.O., F.O.371/677, Z3178. Despacho n610, secreto. De Ernest Bevin a Duff Cooper. 13/05/1947. Despachos $\mathrm{n}^{\mathrm{D}}$ 138, 115, 91, 110 y 238, confidencial. Del Foreign Office a W.E. Houstoun-Boswall. 28/06/1 947. 
asuntos exteriores comenzaban a emitir instrucciones a sus diplomáticos, destinadas a una mejora de las relaciones anglo-francesas ${ }^{32}$.

El "entendimiento" fue breve. No sólo por las condiciones en las que se había promovido, sino por los sucesos que vinieron a coincidir en aquellos mismos días, afectando gravemente a las relaciones franco-egipcias. El rey Faruq por entonces estaba interesado en promover una propaganda política por el mundo árabe que le garantizara el prestigio de líder indiscutible. Desde hacía unos meses, los egipcios intentaban perturbar a la administración francesa en Túnez, con el envío de provisiones sin dar cuenta a las autoridades. La intervención de Egipto, contraria a los intereses de Francia, parecía que iba a tener como consecuencia inmediata un acercamiento entre franceses y británicos en la zona. Esta cuestión empezó a adquirir especial relevancia sobre el resto de los problemas. Bonneau, director del Departamento de África y Levante en el Quai d'Orsay, solicitó una reunión para tratar aspectos concretos de política y economía acerca del país árabe ${ }^{33}$. Gran Bretaña que no estaba interesada en la coordinación de acciones sobre el terreno, sino en el apoyo en las Naciones Unidas, se mostró más preocupada por el tema de Palestina, dando una negativa a la intención francesa. No obstante, aunque Bonneau prestó gran atención para una mayor colaboración, ya de estas conversaciones se podía deducir un distanciamiento entre los propósitos de unos y otros $^{34}$. Mientras, Francia insistía en el tema egipcio por la repercusión que tenía para ella la acción del rey Faruq y confesaba los vanos intentos de esta nación para ganarse al gobierno de París a través de la cuestión del Sudán ${ }^{35}$. Gran Bretaña insistía en el tema palestino, tratando de convencer a los franceses de lo desventajoso que podía resultar para ellos mismos esa política que impedia neutralizar la llegada de judíos a los territorios árabes. El Quai d'Orsay estaba seguro de que la única repercusión importante que se podria derivar de este problema era el eco que encontrara en la Liga de Estados Arabes. Para ellos era un instrumento británico de poca efectividad, que desaparecería una vez resuelto el problema palestino $^{36}$.

Inmediatamente después de estas conversaciones, el gobierno egipcio logró reunir un cargamento de trigo que fue enviado a Túnez. Al barco "Emira Fawzía", que lo transportaba, se le denegó el permiso para descargar por lo que partió hacia Malta, donde fue recibido por las autoridades británicas cordialmente. Bidault juzgó este hecho como una "farsa provocativa" del monarca egipcio. Paralelamente a este hecho, se produjo la fuga de Abd el Krim, pues el gobierno egipcio le concedió asilo político en unas circunstancias muy poco claras.

32 P.R.O., F.O. 371/67712. Despacho $n^{\circ} 465$ de Ashley Clarke, encargado de negocios en Paris, al Foreign Office. 28/5/1947. La fecha de este documento adquiere una gran importancia para analizar el proceso de cooperación.

33 P.R.O., F.O. 371/67712. Despacho n 465 de Ashley Clarke al Foreign Office. 28/5/1947.

34 P.R.O., F.O. 371/67712. Carta confidencial de J.E. Coulson, de la embajada de Paris, a D.W. Lascelles, del Foreign Office. 23/7/1947.

35 P.R.O., F.O. 371/67712. Carta de Ashley Clarke a Nevile Butler del Foreign Office. 30/5/1947. 
En el verano, al margen de las tensiones en las colonias, la reconstrucción europea a través de la ayuda económica norteamericana del Plan Marshall, hacía evidente la necesidad de la cooperación franco-británica en los asuntos continentales. En junio, tras la presentación de este programa ${ }^{37}$, las capitales europeas plantearon sus necesidades. Ninguna de estas peticiones fue aceptada puesto que en ellas se traducia un espíritu de competencia y desunión, contrario a la intención de los Estados Unidos con su apoyo económico. Estas circunstancias obligaron a que se reunieran los ministros de Asuntos Exteriores de Gran Bretaña, Francia y la Unión Soviética, con el fin de alcanzar un acuerdo previo entre ellos. Era una condición imprescindible. El resultado fue el alejamiento definitivo de esta política de los soviéticos, mientras que franceses y británicos coordinaban sus posturas y emitian un llamamiento conjunto a veintidós naciones europeas. A la convocatoria de París del 12 de julio, respondieron quince naciones occidentales, los otros seis renunciaron a la asistencia situándose bajo la órbita de Moscú ${ }^{38}$. Desde ese momento se puso en marcha la creación de un sistema que, a través de unos organismos reguladores, permitiera la articulación del Plan Marshall. Estas circunstancias favorecieron el acercamiento entre Paris y Londres.

En septiembre, nuevas conversaciones volvieron a plantear una amplia colaboración en el tema comercial, turístico y colonial. Esta vez se trasladaron las responsabilidades a las altas esferas de la administración. Bevin se entrevistó directamente con el presidente del Consejo, Ramadier. Le propuso una cooperación de manera que, especialmente a través de la influencia que les conferían sus dos imperios coloniales, pudieran equiparar su poder al de las superpotencias ${ }^{39}$.

Las reacciones en el Quai d'Orsay fueron diversas. Esta iniciativa británica no mereció ninguna consideración por parte de Chauvel, quien suspicaz como consecuencia de los contactos anteriores, la juzgó de "vacua". A Massigli, el anterior le había parecido demasiado despectivo en su opinión. El embajador no valoró esta proposición con tanto desprecio. Por el contrario, trataba de explicar las razones: a Bevin el temor a un mundo dominado por Estados Unidos y la Unión Soviética cada vez más patente, le había suscitado un sincero interés por la unidad anglo-francesa. Además, la cooperación con Bidault en el Plan Marshall, había demostrado a los británicos las ventajas de trabajar con un gobierno serio como el de París, lo que anteriormente pareció dudoso.

Los deseos del Foreign Office por continuar con las conversaciones y el anuncio de que se estaba estudiando una cooperación económica con Francia a principios de octubre, parecían apuntar a que se entraba en un período en el cual iba a ser posible, definitivamente, el entendimiento de los dos países en materia colonial. Auriol, presidente de la República, se mostró muy interesado dado que veía en estas circunstancias la oportunidad para reducir la dependencia de los europeos de la ayuda americana a través de una mejor explotación de los recursos coloniales.

37 Discurso pronunciado por Marshall, Secretario de Estado, en la Universidad de Harvard el 5 de junio de 1947.

38 FLORENSA, S. "El Plan Marshall" en Historia Universal del siglo XX. La guerra fria. Madrid, Historia 16, Fascículo $\mathrm{n}^{\circ}$ 21, 1984. Pp. 91-102.

39 YOUNG, J.W. Op. Cit., p.168. 
Mediante la intervención de Alphand, inspector de Finanzas en el Quai d'Orsay, fueron resucitados los planteamientos que ya en 1944 habian surgido entre oficiales británicos, franceses, belgas, portugueses y sudafricanos para un acercamiento de las políticas imperiales en las zonas sub-saharianas, donde los movimientos nacionalistas estaban todavía poco evolucionados. Siguiendo este antecedente, en aquellos momentos, se propuso a Gran Bretaña una unificación aduanera del África Occidental. De haber tenido éxito esta idea, la unión de los dos territorios hubiera constituido la base para esa "tercera fuerza" que deseaban tantos franceses, y que estaba próxima al pensamiento de Bevin. Pero esta idea era tan impracticable como ambiciosa. Las filosofias coloniales de Francia, "asimilación", y la de Gran Bretaña, "asociación", hacían imposible su admisión.

En las semanas siguientes, coincidiendo con las resoluciones de Naciones Unidas, favorables al gobierno de Londres al tratarse las cuestiones árabes, el pesimismo presagiado por Chauvel se cumplía. París apenas volvió a tener noticias de los grandes proyectos que defendía Bevin. Los funcionarios británicos para los asuntos económicos, estuvieron poco dispuestos a dar prioridad al comercio con Francia; por razones financieras no era posible una intensificación del turismo, y la unidad aduanera ya en Europa resultaba perjudicial para el comercio de la Commonwealth"

En pocas palabras, las esperanzas que habían surgido al termino del verano, como en las ocasiones anteriores, comenzaron a frustrarse. Habia suficientes causas que explicaban las dificultades en un entendimiento que era reconsiderado por Gran Bretaña. No sólo eran los distintos modelos que utilizaron para resolver la situación imperial, sino que además habría que destacar algunos otros aspectos: El territorio sub-sahariano, que suponía la parte más importante de las posesiones francesas, era enorme y estaba sin desarrollar. Esto significaba que para llegar a ser aprovechable se requerían grandes inversiones, en una Europa que por entonces estaba reconstruyendo sus propios territorios metropolitanos. Existian recelos entre las autoridades locales, que veian en estos proyectos una amenaza para su autoridad y un aumento de trabajo, para el cual no se contaba con suficientes funcionarios. Los británicos eran enemigos de planes idealistas, incluso Bevin que aun siendo grandioso en sus proyectos luego era muy pragmático a la hora de aplicarlos.

Por último, existía una desigualdad en cuestiones militares. Por una parte, estaba la debilidad del ejército francés, y por otra, Londres desconfiaba de la seguridad y de los planteamientos estratégicos centrados en el norte de Áfrcia, en vez del Próximo Oriente.

Ante este panorama, después de las conversaciones entre Bevin y Ramadier, el Foreign Office se opuso a una acción precipitada en las materias coloniales. Todo este proceso terminaba cuando Bidault trasmitía su critica opinión acerca de la unión anglo-francesa en "L'Aube", sorprendiendo a los funcionarios británicos. Ya en 1940 se había propuesto al gobierno de Londres un proyecto de unión para defender el imperio francés contra los ataques de Hitler, pero ni entonces, ni en aquellos años de la posguerra, la situación les había parecido lo suficientemente desesperada como para colaborar.

40 YOUNG, J.W. Op. Cit., p.168. 
En conclusión, la falta de entendimiento entre Gran Bretaña y Francia, convirtieron en inútiles todos los esfuerzos por llegar a una cooperación a fin de mantener sus imperios coloniales, con lo que ello significaba en la sociedad internacional. Estas circunstancias, a la larga, permitieron el ascenso de la corriente descolonizadora que desde las Naciones Unidas, respaldado por las dos superpotencias, garantizó el derecho a la independencia de los pueblos colonizados. Prácticamente en poco más de una década, los dos grandes imperios habían desaparecido. 